\title{
Response of an archaeal community from anoxic coastal marine sediments to experimental petroleum contamination
}

\author{
Gilles Miralles, Monique Acquaviva, Jean-Claude Bertrand, Philippe Cuny*
}

Laboratoire de Microbiologie, Géochimie et Ecologie Marines, UMR 6117, Centre d'Océanologie de Marseille, CNRS, Université de la Méditerranée, Campus de Luminy, Case 901, 13288 Marseille, France

\begin{abstract}
To achieve a better understanding of the ecological significance of Archaea in relation to petroleum contamination, we examined the composition of archaeal communities in anoxic coastal marine infralittoral sediments and their response to simulated petroleum contamination. Sediments were collected at an experimental site, and half were mixed with oil. Control and oiled sediments were then reworked into PVC cores that were inserted into the sediment at their sampling site at $20 \mathrm{~m}$ water depth. After $503 \mathrm{~d}$ of in situ incubation, molecular and statistical analyses clearly showed that petroleum contamination induced significant shifts in the composition of archaeal communities inhabiting these anoxic sediments. Overall, contamination led to a significant decrease in diversity. Control sediments were dominated by Crenarchaeota, whereas in oiled sediments, Euryarchaeota became dominant, as attested by the particular contribution of Methanococcoides, Methanosarcina, and Methanolobus sequences. Methanogens could be indirectly related to the degradation of the added hydrocarbons by participating in syntrophic consortia with hydrocarbon-degrading acetogenic bacteria. In addition, the abundance of anaerobic methane-oxidizing Archaea sequences in oiled sediments could indicate that anaerobic oxidation of methane (AOM) occurs at the depth selected for the analyses. Further studies undertaken to quantify vertical distribution of AOM, methanogenic activity, and their potential causative Archaea would help to enhance understanding of this complex petroleum-contaminated sedimentary system.
\end{abstract}

KEY WORDS: Archaea · Petroleum contamination · Anoxic coastal sediments · Hydrocarbon degradation

\section{INTRODUCTION}

Human activities often result in large-scale pollution of soil, water, and sediments by petroleum or its refined products. Microbial biodegradation is among the principal routes by which petroleum hydrocarbons are removed from the environment (Widdel \& Rabus 2001, Head et al. 2006), in particular in marine sediments (Muschenheim \& Lee 2002). Bacteria are generally considered to be the predominant agents of these processes, and consequently in situ response of bacterial communities to both oiling and bioremediation treatments have been investigated so far (e.g. Macnaughton et al. 1999, Miralles et al. 2007b). In contrast, little attention has been paid to Archaea, and the few studies conducted to date were focused on singular ecosystems exposed to petroleum such as petroleum reservoirs, underground crude oil storage cavities, polluted aquifers, or natural oil seeps (Magot et al. 2000, Orphan et al. 2000, Watanabe et al. 2002, Kleikemper et al. 2005). However, Archaea are a diverse and widespread group that occur worldwide (Bintrim et al. 1997, DeLong 1998, Boetius et al. 2000, Jurgens et al. 2000). We therefore expected that archaeal populations might play a significant role in the response of microbial communities to petroleum contamination in nonextreme environments. Archaeal populations have been found in microbial communities engaged in 
anaerobic petroleum hydrocarbon degradation (Ficker et al. 1999, Zengler et al. 1999). Recently, Orcutt et al. (2008) reported interesting observations on the relationship between presence of oil, methanogenesis, and anaerobic oxidation of methane (AOM), both processes realized by Archaea. The aim of the present study was to examine by clone library comparison the composition of archaeal communities in anoxic coastal marine infralittoral sediments and their response to petroleum contamination under experimental conditions.

\section{MATERIALS AND METHODS}

Site description, field experiment, and sampling. This study is part of a field experiment conducted in the Gulf of Fos (Mediterranean Sea) under experimental conditions. Full details concerning the field site and experimental setup have been published previously (Miralles et al. 2007b). Briefly, sediments were collected at an experimental site located in the Gulf of Fos $\left(43^{\circ} 22.364^{\prime} \mathrm{N}, 4^{\circ} 59.674^{\prime} \mathrm{E}\right)$ at $20 \mathrm{~m}$ water depth. At this site, temperature ranges from 9 to $19^{\circ} \mathrm{C}$ and salinity ranges from 30 to 38 (depending on seasons, wind forcing, solar radiation, freshwater discharges from the Rhône River and Berre pond and other factors). Sediments were classified as clayey silts (clay $<4 \mathrm{~mm}=$ $26.4 \%$, silt $=60.0 \%$, sand $=13.6 \%$ ) and contained $27.7 \pm 2.7 \%$ water and $10.52 \pm 0.98 \%$ total organic matter. Total hydrocarbon content was $0.29 \pm 0.03 \mathrm{~g}$ $\mathrm{kg}^{-1}$ dry wt. Sediments were sieved on a $1 \mathrm{~mm}$ mesh in order to remove benthic macrofauna. Half of the sediments were mixed with blend Arabian light oil (BAL) at a ratio of $20 \mathrm{~g} \mathrm{~kg}^{-1}$ wet wt by mechanical stirring (3 h). Saturated hydrocarbons, aromatic hydrocarbons, resins, and asphaltenes contributed, respectively, $65.8 \%, 22.1 \%, 8.8 \%$, and $3.3 \%$ of BAL, which had a density of $0.858 \mathrm{~g} \mathrm{~cm}^{-3}$ and sulfur content of $1.8 \%$. Control sediments were subjected to the same treatment (mechanical stirring for $3 \mathrm{~h}$ ), but without the BAL contamination. Control (CONT) and oiled (OIL) sediments were reworked into PVC cores $(25 \mathrm{~cm} \times 11 \mathrm{~cm}$ i.d.) and frozen at $-20^{\circ} \mathrm{C}$. CONT and OIL cores were then inserted, with the top and bottom opened, into the sediment at the field site at $20 \mathrm{~m}$ water depth by SCUBA diving. PVC protruded about $1 \mathrm{~cm}$ above the sediment/water interface.

The long-term effects of petroleum on archaeal community composition were studied after $503 \mathrm{~d}$ of in situ incubation. Cores were collected in triplicate. Vertical distribution patterns of pore-water oxygen concentration and luminophores (inert particles used as tracers to study sediment reworking by bioturbating organisms) were similar in CONT and OIL sediments. They indicated that only the uppermost 2 to $3 \mathrm{~mm}$ were permanently oxygenated and that the maximum depth of luminophore penetration was $6 \mathrm{~cm}$ (Miralles et al. $2007 \mathrm{~b}$ ) indicating that below this depth there was no bioturbation effect. Cores were sliced into 1 and $2 \mathrm{~cm}$ thick layers, and archaeal community response to oiling was assessed at 8 to $10 \mathrm{~cm}$ depth, which was a strictly anoxic layer where no bioturbation processes occurred.

Nucleic acid extraction, PCR amplification of $16 \mathrm{~S}$ rRNA encoding genes, cloning, and sequencing of amplification products. Genomic DNA was extracted from sediment duplicates $(350 \mathrm{mg}$ ) of the 8 to $10 \mathrm{~cm}$ depth of each of the 3 CONT and OIL cores using the UltraClean Soil DNA kit (MoBio laboratories) including the inhibitor-removal step and the optimized protocol for maximum yield. Before performing amplification, DNA replicates (3 identical cores by duplicate extractions, $3 \times 2=6$ samples) were combined in proportional quantities. 16S rRNA encoding genes were amplified from $40 \mathrm{ng}$ of genomic DNA with the universal archaeal primers 344F (5'-ACG GGG YGC AGC AGG CGC GA-3') and 934R (5'-GTG CTC CCC CGC CAA TTC CT-3') (Baker et al. 2003). The PCR was performed using a $50 \mu \mathrm{l}$ (total volume) mixture containing $5 \mu 10 \times$ amplification buffer, $200 \mu \mathrm{M}$ of each deoxyribonucleotide triphosphate (dNTP), $1 \mu \mathrm{M}$ of each primer, and $2 \mathrm{U}$ of Taq polymerase Triple Master (Eppendorf). Amplification was carried out in a DNA thermal cycler (Eppendorf Mastercycler personal). The reaction started with $5 \mathrm{~min}$ denaturation at $94^{\circ} \mathrm{C}$, continued with 35 cycles of $1 \mathrm{~min}$ denaturation at $94^{\circ} \mathrm{C}, 30 \mathrm{~s}$ annealing at $56^{\circ} \mathrm{C}$, and $35 \mathrm{~s}$ elongation at $72^{\circ} \mathrm{C}$, and finished with $10 \mathrm{~min}$ elongation at $72^{\circ} \mathrm{C}$.

PCR products were then excised from a $1 \%$ agarose gel and purified with the Wizard SV Gel and PCR Clean-Up System (Promega). Purified PCR products were ligated into pGEM-T Easy Vector System (Promega), and the ligation products were transformed into JM109 high efficiency competent cells with ampicillin and blue/white screening. Positive clones were cultivated overnight on liquid Luria-Bertani medium containing $100 \mu \mathrm{g} \mathrm{ml}^{-1}$ ampicillin. The screening of inserts from the transformants was performed by PCR amplification with standard SP6 and T7 promoter primers, after plasmid extraction with the Wizard plus SV Miniprep DNA purification System (Promega). Clones were clustered in operational taxonomic units (OTUs) by comparing the restriction fragment length polymorphism (RFLP) patterns that resulted from 2 individual digestions with HaeIII and AluI enzymes (Promega) followed by $5 \%$ polyacrylamide gel electrophoresis. A number of clones proportional to the number of clones of each OTU was selected for 
sequencing, performed using the ABI PRISM BigDye Terminator v 1.1 Cycle Sequencing Kit (Applied Biosystems) and T7 promoter primer. Sequencing was performed by Génomique Fonctionnelle de Bordeaux (www.pgfb.u-bordeaux2.fr/eng/index.html).

Diversity indices, phylogenetic analyses, and LIBSHUFF comparison. Rarefaction analysis was performed on RFLP data using the Analytic Rarefaction program v 1.3 (www.uga.edu/ strata/software/), and various indices (Dominance, Shannon $\left[H^{\prime}\right]$, and Simpson $[D])$ were calculated for each clone library using the Paleontological Statistics (PAST) software v 1.74 (http://folk.uio.no/ohammer/past/index.html) (Hammer et al. 2001). The non-parametric Chao-1 estimator for species richness was also calculated (Chao 1984). Sequences obtained were submitted to DDBJ/RMBL/ GenBank databases under accession numbers EU503229 to EU503342. Sequences were initially analyzed with the ARB software package (www.arbhome.de/) (Ludwig et al. 2004). They were inserted into an established alignment of 1344 archaeal 16S rRNA sequences kindly provided by Dr. G. Jurgens (Schleper et al. 2005). A backbone tree was first generated by using maximum likelihood, and our sequences were inserted into the reconstructed tree by using parsimony criteria in order to roughly determine their phylogenetic position. Then, sequences were aligned with the same region of closest relative strains and uncultured clones with the ClustalX program (Thompson et al. 1997). Evolutionary distances were calculated from pairwise sequence similarities with the Kimura 2-parameter model for nucleotide change using the MEGA4.0 software, and phylogenetic trees were constructed using the neighbor-joining method (www.megasoftware.net/) (Tamura et al. 2007). One thousand bootstrap resamplings were performed to estimate the reproducibility of trees. The similarity of CONT and OIL clone libraries was evaluated by using the LIBSHUFF software (http://libshuff.mib.uga.edu/) (Singleton et al. 2001). As shown by Singleton et al. (2001), it is assumed that if the 2 libraries are significantly different, the original $\Sigma \Delta C$ will be higher than the vast majority of $\Sigma \Delta C^{\prime}$ of shuffled samples. The 2 libraries are considered significantly different when $\mathrm{p}<0.05$.

\section{RESULTS}

\section{Rarefaction analysis and diversity indices of CONT and OIL clone libraries}

In total, 151 and 126 archaeal 16S rRNA sequence clones were recovered, and RFLP analysis gave 81 and 26 different OTUs for the CONT and the OIL clone
Table 1. Diversity indices and coverage values calculated for the 2 clone libraries. CONT: control sediments, OIL: oiled sediments, OTU: operational taxonomic unit

\begin{tabular}{|lcc|}
\hline & \multicolumn{2}{c|}{ Clone library } \\
& CONT & OIL \\
\hline Number of sequences & 151 & 126 \\
OTU & 81 & 26 \\
Singletons & 61 & 16 \\
Coverage $(\%)$ & 59 & 89 \\
Dominance & 0.05 & 0.10 \\
Shannon $\left(H^{\prime}\right)$ & 3.82 & 2.61 \\
Simpson $(D)$ & 0.95 & 0.90 \\
Chao-1 estimator & $249 \pm 45$ & $154 \pm 66$ \\
& & \\
\hline
\end{tabular}

libraries, respectively (Table 1). For the CONT library, 61 OTUs consisted of a single member (singletons), whereas only 16 singletons were counted in the OIL library. The diversity coverage value of the OIL library was higher $(89 \%)$ than that of the CONT library (the low value of $59 \%$ indicated a possible underestimation of clone diversity). This was also indicated by rarefaction curves, which approached a plateau confirming good biodiversity coverage for the OIL library but did not indicate saturation for the CONT (data not shown). Table 1 shows Dominance, Shannon $\left(H^{\prime}\right)$, and Simpson $(D)$ diversity indices calculated for each library. The Dominance was 2-fold higher for the OIL library than for the CONT library. By contrast, diversity indices were higher for the CONT library than for the OIL library. The non-parametric Chao-1 estimator was used to extrapolate information from observed frequencies of OTUs to predict the number of different taxa in the samples. As for diversity indices, Chao-1 was greater for the CONT library $(249 \pm 45)$ than for the OIL library $(154 \pm 66$; Table 1$)$.

\section{Distribution of archaeal clones and representation of archaeal divisions for each sample}

The phylogenetic analysis of the $107(=81+26)$ representative clone sequences revealed that they were distributed within 10 major taxonomical groups of Euryarchaeota and Crenarchaeota. We failed to affiliate with certainty 24 representative sequences $(36.7 \%$ of the clones analyzed) for the CONT library and 6 representative sequences ( $16.4 \%$ of the clones analyzed) for the OIL library. The vast majority of clones were affiliated to archaeal sequences retrieved from marine ecosystems (Supplement 1, Figs. S1 \& S2; available in AME Supplementary Material at www.int-res.com/ articles/suppl/a059p025_app.pdf). Sequences affiliated to Methanococcoides, Methanosarcina, Group I.2, and marine benthic group B/deep sea archaeal group 
Table 2. Relative abundance of identified archaeal groups as determined by RFLP analysis of control sediment (CONT) and oiled sediment (OIL) libraries. The threshold to determine the taxonomic identification was $97 \%$ sequence identity. DHVE6: deep sea hydrothermal vent Euryarchaeota cluster 6; MBGB/DSAG: marine benthic group B/deep sea archaeal group

\begin{tabular}{|lcc|}
\hline \multirow{2}{*}{ Taxonomic identification } & \multicolumn{2}{c|}{ Percent in each library } \\
& CONT & OIL \\
\hline Euryarchaeota & & \\
Methanococcoides & 26.7 & 43.8 \\
Methanolobus & - & 2.3 \\
Methanosarcina & 0.7 & 11.7 \\
Marine group III & 4.7 & - \\
Thermoplasmata & 0.7 & - \\
DHVE6 & 0.7 & - \\
PENDANT-33 & 0.7 & - \\
No clear identification & 0.7 & 14.8 \\
Crenarchaeota & & \\
Group I.2 & 26.0 & 0.8 \\
MBG-B/DSAG & 2.0 & 25.0 \\
Group I.1B & 1.3 & - \\
No clear identification & 36.0 & 1.6 \\
\hline
\end{tabular}

(MBG-B/DSAG) were shared by the 2 libraries, although to a different extent. The relative abundance of clones affiliated to Methanococcoides, Methanosarcina, and MBG-B/DSAG increased after petroleum contamination $(26.7 \%$ in the CONT library versus $43.8 \%$ in the OIL library, 0.7 versus $11.7 \%$, and 2.0 versus $25.0 \%$ ), whereas the relative abundance of clones affiliated to Group I.2 Crenarchaeota (Schleper et al. 2005) decreased (26.0 versus $0.8 \%$; Table 2). Also, Thermoplasmata, DHVE6, PENDANT-33 (Bowman \& McCuaig 2003), and Group I.1B (Quaiser et al. 2002) affiliated sequences detected in the CONT library were absent in the OIL library. Methanolobus sequences were absent in the CONT library but were detected in the OIL library (Table 2).

\section{Comparison of CONT and OIL library by LIBSHUFF analysis}

In an attempt to determine whether CONT and OIL libraries were significantly different, rather than assuming that these 2 libraries correspond to the same community but were sampled twice with different coverage, we applied the LIBSHUFF method, which enables the comparison between libraries based on their sequences (Singleton et al. 2001). Fig. 1 shows the homologous coverage curves $\left(C_{\mathrm{CONT}}\right.$ and $\left.C_{\mathrm{OIL}}\right)$, the heterologous coverage curves $\left(C_{\mathrm{CONT} / \mathrm{Ol}}\right.$ and $C_{\mathrm{OIL}}$ CONT), $\Delta C$, and the 950th values $(\mathrm{p}=0.05)$ of $\Delta C$ for the randomized samples as a function of evolutionary distance $(D)$. Comparisons of CONT versus OIL and OIL

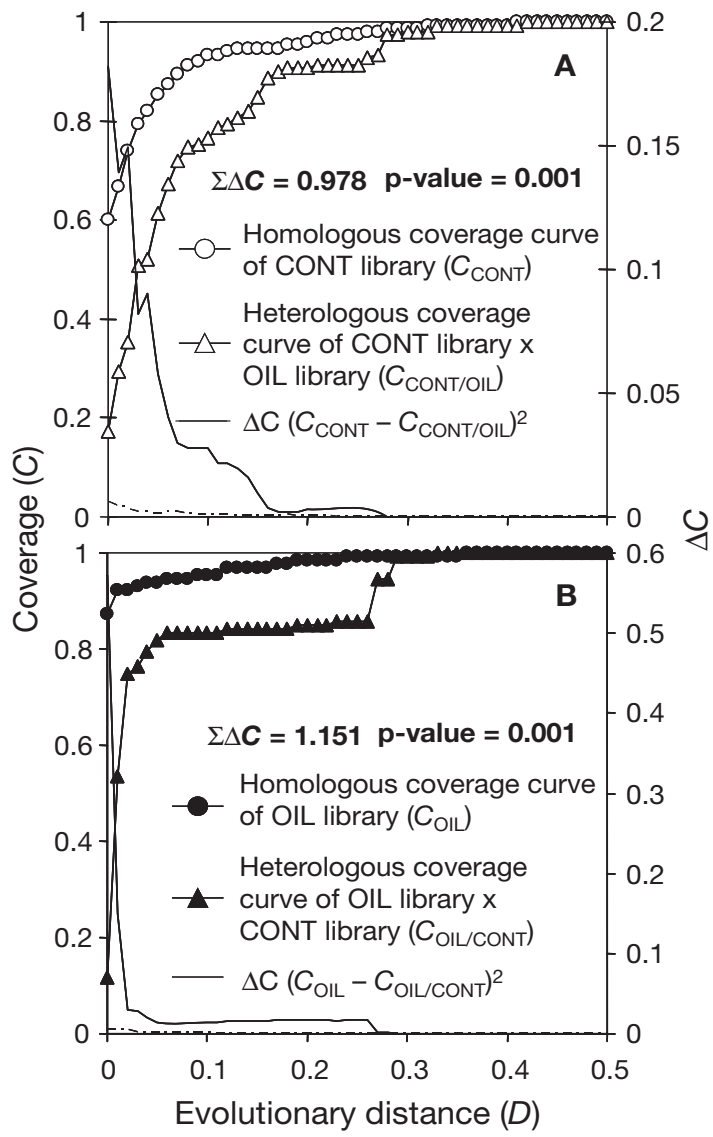

Fig. 1. Results of LIBSHUFF comparisons. (A) Control sediment $(\mathrm{CONT})$ library $(X)$ vs. oiled sediment (OIL) library $(Y)$ and (B) OIL library $(Y)$ vs. CONT library $(X)$. In each case, homologous curve $\left(C_{X}, C_{Y}\right.$, circle), heterologous curve $\left(C_{X Y}\right.$ $C_{Y X}$, triangle), and $\Delta C\left(\left[C_{X^{-}}-C_{X Y}\right]^{2},\left[C_{Y}-C_{Y X}\right]^{2}\right.$, solid line) are presented as a function of evolutionary distance $(D)$. For each comparison, $\Sigma \Delta C$ and the corresponding $\mathrm{p}$-value (corresponding to the rank of $\Sigma \Delta C$ within the entire list of the 999 shuffled samples $\Sigma \Delta C^{\prime}$ ) are indicated. Broken lines indicate the 950th value $(\mathrm{p}=0.05)$ of $\left(C_{X}-C_{X Y}\right)^{2}$ and $\left(C_{Y}-C_{Y X}\right)^{2}$ for the randomized samples in Panels A and B, respectively

versus CONT revealed that the 2 libraries were significantly different from each other $(p=0.001$ for each comparison). More information on the nature of this difference was obtained by examination of the distribution of $\Delta C$ with $D$ (Fig. 1A). At low $D$ (ca. 0.15), the actual $\Delta C$ exceeded the comparable values at $\mathrm{p}=0.05$ obtained during the calculation of $\Delta C^{\prime}$ (broken lines). This result suggested that the libraries differed greatly at $D<0.15$ but shared many deep taxa. However, smaller differences at $D>0.2$ suggested that not all deep phylogenetic groups were found in both libraries. By examining the distribution of $\Delta C$ with $D$ in Fig. 1B, it can be concluded that taxa identified in the OIL library were also present in the CONT library but many taxa contained in the CONT library were absent in the OIL library. 


\section{DISCUSSION}

This study was part of a larger experiment designed to examine the fate of petroleum hydrocarbons in infralittoral coastal marine sediments and their impact on prokaryote community composition under experimental conditions. We previously reported that contamination induced significant shifts in the structure of the indigenous bacterial communities associated with a typical microbial alteration of added $n$-alkanes (Miralles et al. 2007b). In our oiled sediments, predominant bacteria were closely affiliated to hydrocarbonoclastic sulfate-reducing bacteria (SRB, belonging to Desulfococcus-Desulfonema-Desulfosarcina-like and to Desulfovibrio-Desulfomicrobium-like groups) which probably contributed to the alkane biodegradation as also reported by several authors (e.g. Aeckersberg et al. 1998, Harms et al. 1999, Cravo-Laureau et al. 2004, Kniemeyer et al. 2007). Our experimental protocol was shown to perturb bacterial communities for several months, but after $503 \mathrm{~d}$, the protocol-induced changes disappeared (Miralles et al. 2007b). Preparation of cores by this protocol (including homogenization and freezing) inevitably induced, among other things, the oxygenation of anoxic sediments and the redistribution of prokaryotic communities. The observed community was established from a perturbed natural community and recolonization. However, after 503 d, bacterial community structures of control cores and non-manipulated cores directly inserted into the sediment were similar (Miralles et al. 2007b). Thus, for the present study, we chose to make the comparison of CONT and OIL cores after $503 \mathrm{~d}$ to avoid as much as possible the protocol influence on archaeal communities. Also, the 8 to $10 \mathrm{~cm}$ depth was chosen because it was shown to be strictly anoxic (only the first 2 to $3 \mathrm{~mm}$ were oxygenated, and the maximum depth of luminophore penetration was $6 \mathrm{~cm}$ ). Moreover, at this depth and at this time, despite a significant degradation of the lighter fraction, a large quantity (about $17 \mathrm{~g} \mathrm{~kg}^{-1}$ ) of oil remained (Miralles et al. 2007a).

The PCR-based strategy used in this study for phylogenetic analysis could have introduced strong biases associated with PCR of the 16S rRNA gene (Farrelly et al. 1995, von Wintzingerode et al. 1997). These possible effects may mean that the proportions found in the clone libraries do not always represent the 16S rRNA gene proportion within microbial communities. However, the molecular phylogenetic approach using PCR and 16S rRNA gene cloning is at the moment the most accurate technique available for describing the composition of complex microbial communities and gaining at the very least a descriptive overview of possible differences and comparability between different environmental samples (Yakimov et al. 2005).
In the present study, we have clearly shown that petroleum contamination induced significant shifts in the composition of the archaeal community inhabiting anoxic coastal sediments incubated at $20 \mathrm{~m}$ depth. In control sediment, a high diversity was observed and Crenarchaeota represented about two-thirds of the archaeal clone library. However, we failed to affiliate with certainty $36.7 \%$ of the clones analyzed. After petroleum contamination, a strong decrease in archaeal diversity was recorded, as shown by the Shannon and Simpson indices and the Chao-1 estimator, and the proportion of clones with no clear affiliation decreased to $16.4 \%$. In oiled sediments, the community was dominated by Euryarchaeota $(72.7 \%$ of the clone library), mainly represented by Methanosarcinales, i.e. Methanococcoides (43.8\%), Methanosarcina (11.7\%), and Methanolobus (2.3\%) sequences. The LIBSHUFF analysis showed that the OIL library differed from the CONT library and confirmed that shifts in archaeal community composition in response to oil contamination were significant. We may therefore speculate as to whether archaeal communities actively established in oiled sediments played a significant role in the observed oil degradation. To our knowledge, only a limited number of hydrocarbonoclastic archaeal strains have been isolated to date. They are all extreme halophilic (e.g. Bertrand et al. 1990, Kulichevskaya et al. 1992, Zvyagintseva et al. 1995) or hyperthermophilic (Stetter et al. 1993) strains. However, no sequence affiliated to these archaeal strains was detected here, and the high number of sequences affiliated to Methanococcoides, Methanosarcina, and Methanolobus sequences could rather indicate that such methanogens play a role in the observed degradation of hydrocarbons.

Methanogenesis is involved in the degradation of a variety of alkanes and aromatic hydrocarbons (Ficker et al. 1999, Parkes 1999, Zengler et al. 1999). However, methanogenic Archaea are not able to degrade petroleum hydrocarbons and as such are dependent on degradative activities of other organisms. Thus, methanogenic degradation processes characteristically involve consortia. In natural environments, the composition of these consortia is typically unknown, but on the basis of analyses of model laboratory systems these are likely to be diverse and dynamic communities that require syntrophic cooperation among several different metabolic groups (Ficker et al. 1999). The hydrocarbon degraders initially metabolize hydrocarbons to acetate and $\mathrm{H}_{2}$. They are known as syntrophs because they require the presence of other anaerobes for their metabolism to be effective (Parkes 1999). The hypothesis that, in our sediments, the contamination induces the development of methanogens that are involved in hydrocarbon degradation cannot 
be ruled out. This hypothesis is strengthened by the fact that a large number of sequences affiliated to Desulfovibrio, which have been detected in laboratory methanogenic consortia and whose hypothetical role is as homoacetogens (Parkes 1999), was detected in our oiled sediments (Miralles et al. 2007a).

\section{CONCLUSIONS}

Our clone library approach has shown substantial diversity in the archaeal communities occurring in coastal sediments and has demonstrated that petroleum contamination induced significant modification in the community composition associated with a strong decrease in diversity. In oiled sediments, methanogenic archaeal sequences were largely detected (present study) together with SRB sequences in association with a microbial alteration of oil (Miralles et al. 2007a). The present research indicates an important role of Archaea in the community's response to petroleum contamination (e.g. in syntrophic interactions). However, these results will have to be confirmed by a largescale experiment designed to survey the time and space evolution of archeal communities in response to oil contamination.

Acknowledgements. This work was carried out as part of the program 'GDR HYCAR no. 1123: Cycles biogéochimiques des hydrocarbures naturels et anthropiques en milieu marin', supported by the Centre National de la Recherche Scientifique (CNRS) and Total. Financial support from the French national program ACI-Ecco (Ecodyn, 'Indhyc') is also acknowledged. We thank C. Ré, R. Graille, F. Zuberer, B. De Ligondès, and V. Grossi for their essential work in the field. We are indebted to $\mathrm{M}$. Paul for carefully checking the English.

\section{LITERATURE CITED}

Aeckersberg F, Rainey FA, Widdel F (1998) Growth, natural relationships, cellular fatty acids and metabolic adaptation of sulfate-reducing bacteria that utilize long-chain alkanes under anoxic conditions. Arch Microbiol 170:361-369

Baker GC, Smith JJ, Cowan DA (2003) Review and reanalysis of domain-specific $16 \mathrm{~S}$ primers. J Microbiol Methods 55:541-555

Bertrand JC, Almallah M, Acquaviva M, Mille G (1990) Biodegradation of hydrocarbons by an extremely halophilic archaebacterium. Lett Appl Microbiol 11:260-263

Bintrim SB, Donohue TJ, Handelsman J, Roberts GP, Goodman RM (1997) Molecular phylogeny of Archaea from soil. Proc Natl Acad Sci USA 94:277-282

Boetius A, Ravenschlag K, Schubert CJ, Rickert D and others (2000) A marine microbial consortium apparently mediating anaerobic oxidation of methane. Nature 407:623-626

Bowman JP, McCuaig RD (2003) Biodiversity, community structural shifts, and biogeography of prokaryotes within Antarctic continental shelf sediment. Appl Environ Microbiol 69:2463-2483
Chao A (1984) Nonparametric estimation of the number of classes in a population. Scand J Stat 11:265-270

Cravo-Laureau C, Matheron R, Cayol JL, Joulian C, Hirschler-Rea A (2004) Desulfatibacillum aliphaticivorans gen. nov., sp. nov., an $n$-alkane- and $n$-alkene-degrading, sulfate-reducing bacterium. Int J Syst Evol Microbiol 54: $77-83$

DeLong EF (1998) Everything in moderation: Archaea as 'non-extremophiles'. Curr Opin Genet Dev 8:649-654

Farrelly V, Rainey F, Stackebrandt E (1995) Effect of genome size and rrn gene copy number on PCR amplification of 16S rRNA genes from a mixture of bacterial species. Appl Environ Microbiol 61:2798-2801

> Ficker M, Krastel K, Orlicky S, Edwards E (1999) Molecular characterization of a toluene-degrading methanogenic consortium. Appl Environ Microbiol 65:5576-5585

Hammer Ø, Harper DAT, Ryan PD (2001) PAST: paleontological statistics software package for education and data analysis. Palaeontol Electron 4:1-9

> Harms G, Zengler K, Rabus R, Aeckersberg F, Minz D, Rossello-Mora R, Widdel F (1999) Anaerobic oxidation of o-xylene, m-xylene, and homologous alkylbenzenes by new types of sulfate-reducing bacteria. Appl Environ Microbiol 65:999-1004

> Head IM, Jones DM, Roling WFM (2006) Marine microorganisms make a meal of oil. Nat Rev Microbiol 4:173-182

> Jurgens G, Glockner FO, Amann R, Saano A, Montonen L, Likolammi M, Munster U (2000) Identification of novel Archaea in bacterioplankton of a boreal forest lake by phylogenetic analysis and fluorescent in situ hybridization. FEMS Microbiol Ecol 34:45-56

> Kleikemper J, Pombo SA, Schroth MH, Sigler WV, Pesaro M, Zeyer J (2005) Activity and diversity of methanogens in a petroleum hydrocarbon-contaminated aquifer. Appl Environ Microbiol 71:149-158

- Kniemeyer O, Musat F, Sievert SM, Knittel K and others (2007) Anaerobic oxidation of short-chain hydrocarbons by marine sulphate-reducing bacteria. Nature 449: 898-902

Kulichevskaya IS, Milekhina EI, Borzenkov IA, Zvyagintseva IS, Belyaev SS (1992) Oxidation of petroleum hydrocarbons by extremely halophilic archaebacteria. Microbiology 60:596-601

Ludwig W, Strunk O, Westram R, Richter L and others (2004) ARB: a software environment for sequence data. Nucleic Acids Res 32:1363-1371

> Macnaughton SJ, Stephen JR, Venosa AD, Davis GA, Chang YJ, White DC (1999) Microbial population changes during bioremediation of an experimental oil spill. Appl Environ Microbiol 65:3566-3574

Magot M, Ollivier B, Patel BKC (2000) Microbiology of petroleum reservoirs. Antonie Leeuwenhoek 77:103-116

Miralles G, Grossi V, Acquaviva M, Duran R, Bertrand JC, Cuny P (2007a) Alkane biodegradation and dynamics of phylogenetic subgroups of sulfate reducing bacteria in an anoxic coastal marine sediment artificially contaminated with oil. Chemosphere 68:1327-1334

Miralles G, Nérini D, Manté C, Acquaviva M and others (2007b) Effects of spilled oil on bacterial communities of Mediterranean coastal anoxic sediments chronically subjected to oil hydrocarbon contamination. Microb Ecol 54: $646-661$

> Muschenheim DK, Lee K (2002) Removal of oil from the sea surface through particulate interactions: review and prospectus. Spill Sci Technol Bull 8:9-18

> Orcutt B, Samarkin V, Boetius A, Joye SB (2008) On the relationship between methane production and oxidation by 
anaerobic methanotrophic communities from cold seeps of the Gulf of Mexico. Environ Microbiol 10:1108-1117

Orphan VJ, Taylor LT, Hafenbradl D, Delong EF (2000) Culture-dependent and culture-independent characterization of microbial assemblages associated with hightemperature petroleum reservoirs. Appl Environ Microbiol 66:700-711

Parkes J (1999) Cracking anaerobic bacteria. Nature 401: $217-218$

Quaiser A, Ochsenreiter T, Klenk HP, Kletzin A and others (2002) First insight into the genome of an uncultivated crenarchaeote from soil. Environ Microbiol 4:603-611

Schleper C, Jurgens G, Jonuscheit M (2005) Genomic studies of uncultivated Archaea. Nat Rev Microbiol 3:479-488

Singleton DR, Furlong MA, Rathbun SL, Whitman WB (2001) Quantitative comparisons of 16S rRNA gene sequence libraries from environmental samples. Appl Environ Microbiol 67:4374-4376

Stetter KO, Huber R, Blochl E, Kurr M and others (1993) Hyperthermophilic archaea are thriving in deep North Sea and Alaskan oil reservoirs. Nature 365:743-745

Tamura K, Dudley J, Nei M, Kumar S (2007) MEGA4: molecular evolutionary genetics analysis (MEGA) software version 4.0. Mol Biol Evol 24:1596-1599

Thompson JD, Gibson TJ, Plewniak F, Jeanmougin F, Higgins DG (1997) The ClustalX windows interface: flexible strate-

Editorial responsibility: Antje Boetius,

Bremen, Germany gies for multiple sequence alignment aided by quality analysis tools. Nucleic Acids Res 25:4876-4882

von Wintzingerode F, Göbel UB, Stackebrandt E (1997) Determination of microbial diversity in environmental samples: pitfalls of PCR-based rRNA analysis. FEMS Microbiol Rev 21:213-229

Watanabe K, Kodama Y, Hamamura N, Kaku N (2002) Diversity, abundance, and activity of archaeal populations in oil-contaminated groundwater accumulated at the bottom of an underground crude oil storage cavity. Appl Environ Microbiol 68:3899-3907

Widdel F, Rabus R (2001) Anaerobic biodegradation of saturated and aromatic hydrocarbons. Curr Opin Biotechnol $12: 259-276$

Yakimov MM, Denaro R, Genovese M, Cappello S and others (2005) Natural microbial diversity in superficial sediments of Milazzo Harbor (Sicily) and community successions during microcosm enrichment with various hydrocarbons. Environ Microbiol 7:1426-1441

Zengler K, Richnow HH, Rossello-Mora R, Michaelis W, Widdel F (1999) Methane formation from long-chain alkanes by anaerobic microorganisms. Nature 401: 266-269

Zvyagintseva IS, Belyaev SS, Borzenkov IA, Kostrikina NA, Milekhina EI, Isanov MV (1995) Halophilic archaebacteria from the Kalamkass oil field. Microbiology 64:67-71

Submitted: May 15, 2008; Accepted: September 21, 2009

Proofs received from author(s): February 1, 2010 